\title{
st \\ Sobre a definição de observação como percepção verdadeira justificada
}

\author{
Alessio GAVA
}

\begin{abstract}
苗
RESUMO

A primazia do ato de observação, um dos traços marcantes do empirismo, está reafirmada no empirismo construtivo de Bas van Fraassen através da centralidade atribuída à distinção entre observável e inobservável. Contudo, como relevado por Elliott Sober (e outros), não está claro o que van Fraassen entende por observar. Pior, ao que parece o filósofo holandês não considera necessário fornecer esclarecimentos a tal respeito. Isso, evidentemente, representa uma lacuna importante na posição que é reconhecidamente considerada como a principal referência do empirismo nos dias de hoje. O objetivo do presente trabalho é retomar as condições contrafáticas que caracterizam a percepção apresentadas por Otávio Bueno nesta revista em 2011, além de levar em conta critérios de observabilidade e de existência propostos por Filip Buekens e Michel Ghins, para alcançar uma definição de observação que deveria fornecer ao conceito fraasseniano de observabilidade o suporte que atualmente lhe falta, mas sem que isso seja proposto como uma solução $a d$ hoc.
\end{abstract}

Palavras-chave • Observação. Percepção. Observabilidade. Empirismo construtivo.

Condições contrafáticas.Van Fraassen. Buekens. Bueno. Ghins. Noë.

O empirismo construtivo, a vertente antirrealista que Bas van Fraassen propôs em The scientific image (1980), está fundamentado na possibilidade, admitida no âmbito da posição epistemológica conhecida como voluntarismo, de manutenção de uma atitude diferente para com as diversas partes de uma teoria científica; crença (epistêmica), que deve ser reservada para suas subestruturas empíricas, ou seja, as partes dos modelos da teoria que representam diretamente os aspectos observáveis do mundo, e mera aceitação (pragmática), algo que pode ser grosseiramente comparado com um "fazer de conta que é verdade", a ser mantida quando a teoria não fala de algo observável e atual.

Existe uma distinção mais básica, como se depreende, que é crucial para a posição empirista do filósofo holandês, a saber, a distinção entre observável e inobservável. Ser empirista, além do mais, significa reconhecer a primazia da observação e essa garante a possibilidade de manter uma postura firme em relação às crenças nela baseadas (e, por conseguinte, nos observáveis). A esse propósito van Fraassen escreve: 
"é possível manter-se empirista sem cair no ceticismo, recusando precisamente as demandas céticas de justificação onde não há motivo para tê-las" (van Fraassen, 1989, p. 178).

Ao que parece, existe uma maneira (estruturalista) de caracterizar as subestruturas empíricas por meio dos chamados modelos parciais que dispensaria o recurso à noção de observabilidade, o que teria vantagens significativas quando da análise da estrutura e da dinâmica das teorias. Para o empirismo construtivo de van Fraassen, todavia, é crucial o conceito de adequação empírica, pois um dos pilares dessa posição antirrealista é a ideia segundo a qual "a ciência visa dar-nos teorias que sejam empiricamente adequadas" (van Fraassen, 2007, p. 33, grifo no original). Isso torna indispensável, para a vertente empirista do filósofo holandês, a noção de observabilidade, de tal modo que nas tentativas de aplicar a abordagem baseada em estruturas parciais ao empirismo construtivo, particularmente à noção de adequação empírica, continua a fazer-se referência aos aspectos observáveis do mundo ou aos fenômenos empíricos, porquanto se trate da mesma coisa (cf. Bueno, 2014; no prelo). Ademais, resulta difícil entender como um modelo parcial possa constituir uma subestrutura empírica de uma teoria científica sem que se faça recurso à noção de observabilidade, considerando que as subestruturas empíricas são definidas por van Fraassen como sendo certas partes dos modelos de uma teoria, candidatas à representação direta dos fenômenos observáveis (cf. van Fraassen, 2007, p. 122).

Carnap (1950) afirmou explicitamente que a tese da realidade do mundo externo é uma pseudoquestão; ao que parece hoje em dia essa tese subjaz um tanto explicitamente no debate entre realismo e antirrealismo (e na filosofia da ciência de forma geral). Tampouco no século xix houve alguém que, pelo menos na filosofia da ciência, tenha posto em discussão a existência de uma realidade independente da mente. A propósito do realismo científico, Chakravarrty escreve que se trata da visão segundo a qual "as teorias científicas descrevem corretamente a natureza de um mundo independente da mente" (Chakravartty, 2007, p. 4), mas esse é um ponto certamente compartilhado pelo empirismo construtivo de van Fraassen (cujo antirrealismo somente significa não aceitar a ideia de que as teorias científicas descrevam corretamente todos os aspectos desse mundo, pois não temos como determinar o valor de verdade das asserções acerca de seus aspectos inobserváveis, e nada tem a ver com a eventual negação da realidade do mundo material). Assim, van Fraassen afirma:

Eu tento ser um empirista e do modo como eu entendo essa tradição (...) ela envolve um realismo do senso comum no qual a referência aos fenômenos observáveis não é problemática: pedras, mares, estrelas, pessoas, bicicletas... (van Fraassen, 2008, p. 3). 
Mas Kosso (2006) e Chang (2005), entre outros autores, expressaram-se de modo inequívoco sobre o fato de que as observações fornecem informação que não podemos controlar segundo nossa vontade e que, portanto, deve ser considerada como sendo acerca de um mundo externo e independente de nossa mente. Essa tese está implicitamente assumida também neste artigo.

Algumas correntes empiristas (ainda que não todas) - e o empirismo construtivo de van Fraassen pode ser contemplado entre elas - tomam a percepção sensorial como ponto de partida para nosso conhecimento da realidade exterior, fato que parece ser razoável (ou até óbvio). I A confiança nas respostas de nosso sistema sensorial aos estímulos externos é, assim, inata e motivada pela capacidade de adaptação ao ambiente que os seres humanos mostraram no decorrer de sua história evolutiva. Sem essa capacidade, a raça humana ter-se-ia extinto.

Nancy Gartwright considera que assim se explica a crença de van Fraassen nos observáveis e que, por essa mesma razão, tais crenças não precisam ser justificadas. Nós temos uma justificação primitiva especial, não epistêmica, para a formação de crenças acerca daquilo que é observável e elas nos ajudam a controlar as experiências e as percepções que nos afetam (cf. Cartwright, 2007, p. 40-4).

Isso não significa que nosso aparelho sensorial seja tomado como certeiro pelos empiristas construtivos, mas os seres humanos são normalmente capazes de reconhecer quando uma percepção é digna de confiança ou não e até de corrigi-la, se necessário. ${ }^{2}$ Vale, portanto, quanto Paul Grice já sustentava há mais de cinquenta anos, ou seja,

quando, em circunstâncias normais, me parece que há uma mesa na minha frente, posso tranquilamente afirmar que há uma mesa na minha frente e recusar qualquer pedido de justificação, a não ser que haja motivos legítimos para duvidar disso (1961, p. 150).

Mas como podemos fazer para saber quando uma percepção é bem sucedida e pode ser legitimamente considerada uma observação? Não se trata de excluir somente

\footnotetext{
1 O uso da locução “ponto de partida”, no caso do empirismo construtivo, deve, porém, ser tomada cum grano salis, pois poderia levar a pensar que van Fraassen é um fundacionalista, enquanto ele nega explicitamente a possibilidade de uma epistemologia fundacionalista.

2 Segundo Paul Humphreys, a ênfase no aparelho sensorial humano (sem instrumentos) como fonte de informação confiável deriva, em parte, da nossa familiaridade com as circunstâncias nas quais ele nos "deixa na mão": "Nós assumimos comumente que nosso uso dos sentidos, mesmo em situações longe das condições ideais, é relativamente não problemático, mas isso está baseado em nossa percepção, bastante refinada, das condições sob as quais as evidências de nossos sentidos deixam de ser confiáveis" (Humphreys, 2004,p. 4,0). Quando não sentimos que há razões para desconfiar dele, fato que acontece por falta (default) quando esse é o caso, em outras palavras, a confiança em nosso aparelho sensorial está bem depositada.
} 
casos extremos, como as alucinações, que tanto ocupam os filósofos da percepção, mas até episódios comuns, como quando, ao apoiar a mão na superfície de madeira de uma mesa, essa nos parece menos fria do que a perna metálica da cadeira sobre a qual estamos sentados.

Por isso, parece apropriado considerar que somente se observa quando uma experiência perceptual é produzida pela interação entre o sujeito percipiente e o objeto percebido de maneira que as propriedades do objeto são corretamente representadas nessa experiência, conforme sugerido por Bueno (cf. 2011, p. 278). Para que isso aconteça, é necessário que haja uma relação de tipo causal entre o modo como as coisas estão de fato e a própria experiência perceptual. Mas acreditar, simplesmente, que a percepção seja o término de uma cadeia causal que começa no objeto percebido é insuficiente (cf. Grice, 1961, 121).

Mesmo que as aparências sejam, ao final das contas, nosso único guia da realidade, com efeito, aquilo que parece ser o caso não pode ser tomado como necessariamente correspondendo àquilo que é o caso. Existe o problema de passar da aparência à realidade. (Com isso somente se quer fazer referência ao hiato que pode existir, por causa da falibilidade de nosso aparelho sensorial, entre "as coisas assim como elas parecem" e "as coisas assim como elas estão de fato". Certamente não é intenção de Grice - nem nossa - entrar em questões metafísicas como a diferença entre fenômeno e noúmeno.) Para resolvê-lo, Grice propôs uma versão da teoria causal da percepção, segundo a qual um sujeito $X$ percebe $M$ se e somente se $M$ é causalmente responsável de um estado de coisas relatado de forma verdadeira por $X$ (cf. Grice, 1961, p. 151-2).

Alva Noë resume a teoria causal de Grice como sendo a afirmação de que um sujeito $S$ vê que $o$ é $F$ se e somente se $S$ tem a experiência visual de $o$ como sendo $F$; $o$ é $F$; e a experiência de $o$ depende, causalmente, do fato de $o$ ser $F$ (cf. Noë, 20o3, p. 93). O mesmo critério pode ser evidentemente aplicado, mutatis mutandis, a todos os sentidos.

A caracterização de Grice, porém, não parece conseguir capturar (não completamente, pelo menos) aquilo que acontece na percepção. O próprio ato de ver não corresponde somente a ter uma experiência visual, ainda que Grice enfatize (com razão) a necessidade de que exista uma dependência causal entre essa experiência e o estado de coisas percebido.

Ademais, segundo o diagnóstico de Noë, a teoria causal de Grice é falha, porque, apesar de especificar o tipo de relação causal correto, negligencia o conteúdo da experiência perceptual que diz respeito à relação do sujeito com o objeto da percepção. Em uma experiência perceptual verídica e genuína, com efeito, é mantida a correta forma de dependência contrafactual tanto na dimensão factual quanto na dimensão perspectiva. Por um lado, se as coisas experienciadas fossem diferentes, elas nos pareceriam diferentes. Por outro, se também nossa relação com as coisas experienciadas 
fosse diferente, elas nos pareceriam diferentes (independentemente do fato de como as coisas estão ter mudado ou não).

A percepção depende tanto de como as coisas estão quanto daquilo que o sujeito percipiente faz, porque ela é não apenas um conceito causal, como também um tipo de ação. Assim, quando percebemos, aquilo que é rastreado, além da maneira como as coisas estão, é a maneira como muda nossa relação com elas. Mas isso não é levado em conta na caracterização de Grice, que, portanto, é deficitária. Ela constitui uma condição necessária, mas não suficiente, para que o sujeito tenha uma experiência perceptual (verídica) genuína (cf. Noë, 2003, p. 99).

Segundo uma proposta diferente de Bueno, a percepção de um objeto depende da satisfação das seguintes condições contrafáticas:

(C1) Se a cena diante de nossos olhos fosse diferente (dada a sensibilidade de nosso aparelho cognitivo), nossa experiência perceptual seria correspondentemente diferente.

(C2) Se a cena diante de nossos olhos fosse a mesma (dada a sensibilidade de nosso aparelho cognitivo), nossa experiência perceptual seria correspondentemente a mesma (Bueno, 2011, p. 278).

Essas condições parecem poder levar em conta ambas as dimensões que, segundo Noë, concorrem para constituir o conteúdo de uma experiência perceptual. Contudo, já que no artigo onde elas foram propostas não se faz menção à possibilidade de a cena diante de nós mudar por causa de um nosso deslocamento ou movimento (talvez por isso ser considerado óbvio ou implícito), parece-nos ser o caso de explicitar essa eventualidade. Diremos, portanto, que uma experiência perceptual constitui-se em uma percepção legítima, se as seguintes condições encontram-se satisfeitas:

(C1) Se a cena diante de nossos olhos fosse diferente (dada a sensibilidade de nosso aparelho cognitivo), por causa de alguma mudança nas coisas assim como elas estão ou por causa de algum deslocamento de nossos olhos com respeito a tais coisas, ou por ambos os motivos, nossa experiência perceptual seria correspondentemente diferente.

(C2) Se a cena diante de nossos olhos fosse a mesma (dada a sensibilidade de nosso aparelho cognitivo), porque nada mudou nas coisas assim como elas estão e não houve nenhum deslocamento de nossos olhos com respeito a tais coisas, nossa experiência perceptual seria correspondentemente a mesma. (Novamente, os mesmos critérios podem ser aplicados, mutatis mutandis, a todos os sentidos.) 
Essas condições contrafáticas podem legitimamente ser chamadas de "relevantes", já que, tanto na dimensão factual, quanto na dimensão perspectiva, é mantida a correta forma de dependência contrafactual, conforme os desiderata de Noë (e conforme de fato acontece na percepção). Por essa mesma razão, não somente são necessárias, como também suficientes para que o sujeito tenha uma experiência perceptual (verídica) genuína.

Ainda assim, como também releva Noë, algum cético poderia imaginar contextos ficcionais (que definir como altamente improváveis é, no mínimo, eufemístico) que satisfazem essas condições contrafáticas, mas nos quais a percepção não acontece pelos canais normais. A melhor resposta, em casos como esses, segundo Noë, é reputar tais percepções genuínas, e não somente verídicas, porque o que interessa é a satisfação das condições supracitadas, que seriam necessárias e suficientes para a atribuição de autenticidade à percepção, e não se isso acontece pelos meios naturais e comuns ou não. Mas isso não parece correto, como veremos. Ao contrário, a melhor maneira de responder parece ser aquela de ignorar as situações que o cético nos convida a imaginar. Como se diz, é bom barrar o cético à porta de entrada, porque, uma vez admitido dentro de casa, não há como obstruir seu poder de destruição. Trata-se de uma opção legítima, considerando a artificiosidade dos exemplos.

Com efeito, se somente imaginando circunstâncias que na realidade nunca se poderão realizar é possível pensar em casos de satisfação das condições contrafáticas relevantes - nos quais fica em aberto a pergunta de se esses constituem ou não instâncias de percepção (verídica) genuína -, então isso indiretamente confirma que tais condições capturam de maneira correta e satisfatória aquilo que acontece em casos ordinários (até incomuns) de percepção. Não é tanto pelo fato de os exemplos citados por Noë serem $a d$ hoc que eles podem ser legitimamente desconsiderados, mas antes pelo fato de, por não representarem eventos possíveis (que podem acontecer ou que poderiam ter acontecido), eles não constituirem uma verdadeira confutação dessa caracterização da percepção.

Trata-se, em outras palavras, de uma situação diferente daquela dos famosos contraexemplos de Gettier para a definição de conhecimento como crença verdadeira justificada. Os exemplos de Noë não refutam a caracterização da percepção por meio das condições contrafáticas relevantes, ao passo que os contraexemplos de Gettier salientam a inadequação de uma definição de conhecimento como crença verdadeira justificada.

Enfim, se tudo que os céticos conseguem imaginar como circunstâncias nas quais as condições contrafáticas relevantes falham nada mais é do que contextos de ficção científica, então elas podem tranquilamente ser vistas como tiros que não atingem o alvo e podem ser desatendidas. Somente devem ser levados em conta os eventos que acontecem em mundos possíveis. 
Contudo, vale ressaltar que a satisfação da primeira condição contrafática faz referência ao fato de que, ainda nas palavras de Noë, "na percepção, o mundo age sobre nós, e nós 'agimos de volta'” (2003, p. 100). A percepção é uma ação e, enquanto tal, envolve nosso corpo por inteiro, incluindo todos os sentidos. Nosso espírito analítico e uma exigência de simplificação (a "mãe” desse espírito, provavelmente) que parece inevitável, se quisermos lidar com fenômenos cuja complexidade inviabilizaria qualquer tentativa de compreensão, levam-nos a analisar a percepção como uma ação que pode ser executada mediante o uso de um único órgão sensorial. Assim, fala-se comumente em percepção visual, percepção tátil etc.

Ora, se a percepção é uma atividade consciente (e por essa razão é correto dizer, por exemplo, que eu não escutei o telefone tocar, nesta madrugada, porque estava dormindo), ${ }^{3}$ a consciência diz respeito ao fato de o sujeito (o corpo dele, pelo menos) estar desperto e vigilante e isso significa que é o corpo em sua totalidade que está ativo quando um estímulo externo o afeta e que coopera para que seja possível decodificar o sinal e a informação que esse estímulo entrega para o sujeito.

Se Pablo diz, "Eu vi Salvador, agora há pouco, na frente da galeria”, ele enfatiza o aspecto visual da interação que teve com seu colega pintor, mas é possível que os dois tenham também conversado sobre o último quadro que Manuel pintou, ou que o cheiro de goiaba (a fruta preferida de seu amigo) tenha ajudado Pablo a reconhecer que se tratava de Salvador etc. Sem contar que, evidentemente, o corpo de Pablo em sua totalidade concorreu para que a percepção fosse bem sucedida: os músculos oculares e aqueles do pescoço para direcionar o olhar, muitos outros músculos para manter-se em posição ereta (supondo que ele estivesse em pé) e, provavelmente, outros sentidos, além da vista, para que ele tivesse uma ideia da posição no espaço de Salvador. Analisar a percepção de Pablo como se ela somente tivesse envolvido seu aparelho visual significaria concentrar-se em um aspecto da mesma, mas esse não poderia ser considerado um relato exaustivo.

Isso fica ainda mais evidente quando, por algum motivo, queremos ter certeza daquilo que estamos percebendo. Se escutamos a voz de uma pessoa conhecida enquanto passeamos pela Avenida Paulista, é instintivo virarmos a cabeça e olharmos para ela. Quando, na Suíça, saíamos da escola depois que tinha nevado a tarde toda, tirávamos a neve da placa para saber qual era nosso carro. Se quero escutar uma música que gosto no rádio e de onde estou não consigo ouvi-la bem, posiciono-me mais perto do aparelho ou aumento o som dele. Pode ser inevitável, por exigências descritivas e de compreensão, relatar as experiências desses exemplos salientando somente o envol-

3 Essa é a opinião de van Fraassen, por exemplo, já que a experiência, segundo ele, é tudo aquilo que acontece a um sujeito do qual ele está ciente (cf. 2001, p. 158; 2008, p. 108, 364, nota 20). 
vimento de um único órgão sensorial ("Ouvi Enrico me chamando, ontem, na Paulista"; "Vi um carro igual ao meu, estacionado aqui perto"; "Escutei a nova música de Paolo Conte, esta manhã, no rádio"), mas ater-se apenas a isso é redutor e pode levar a que se tenha uma ideia errada do que é uma percepção.

Michel Ghins escreve que, se a pergunta sobre quais são os critérios de existência de algo pertence à esfera da metafísica, a questão de quais argumentos podemos aduzir em favor da existência ou da realidade de algo diz respeito à justificação de nossas crenças e, portanto, pertence à esfera da epistemologia. Mas as duas questões caminham juntas e se eu posso justificar a crença na existência de uma caneta azul à minha frente dizendo que a vejo, como faria um empirista - assim como van Fraasen que tem certeza de que cavalos voadores não existem porque nunca se viu um (cf. van Fraassen, 2007, p. 38) -, é porém verdade que a caneta deve satisfazer alguns critérios, para que eu não tenha dúvidas acerca do fato de que a caneta existe realmente e que não estou alucinando. Entre eles, segundo Ghins, está um critério de invariância:

Alguns objetos podem ser deslocados no espaço e manter, segundo o observador, a própria identidade. Ou nós podemos deslocar-nos ao redor deles e, ao mesmo tempo, sentirmo-nos seguros acerca do fato de estarmos percebendo o mesmo objeto (Ghins, 2005, p. 96).

Esse critério, que é ontológico, está certamente em consonância com as condições contrafáticas propostas anteriormente, mesmo essas sendo epistemológicas. Com efeito, tanto no critério de Ghins quanto nas condições contrafáticas de Bueno, fala-se de um deslocamento relativo entre o observador e o objeto (ou estado de coisas) percebido, que permite um rastreamento desse último por parte do sujeito, conforme indicam as condições contrafáticas, de maneira que esse pode sentir-se seguro acerca do fato de estar percebendo o mesmo objeto (que mantém, segundo o observador, a própria identidade).

Assim, podemos depreender que algo a mais do que um simples olhar está envolvido na percepção. Ela é uma ação, que envolve o corpo todo.

Quando, ao invés, faltam as condições de verificabilidade do critério de invariância, pode ser legítimo manter uma postura prudente e crítica com relação àquilo que está (supostamente) sendo detectado. Isso pode acontecer quando o assunto é o uso de instrumentos na prática cotidiana dos cientistas. Com relação àquilo que é detectado por meio de um microscópio, por exemplo, há razões para manter-se prudente, pois, no mínimo, como já admitiu Ian Hacking, dizer que uma entidade microscópica foi observada é "estender" a noção ordinária de observabilidade (cf. Buekens, 1999, p. 25). 
Buekens, fazendo referência a uma acepção de “objeto observável”, proposta por Strawson e Evans e retomada por Peacock, endossa o critério, que parece quase feito sob medida para van Fraassen, segundo o qual um objeto deve poder ser observado e identificado a partir de ângulos diferentes.

É crucial, para nossa concepção de objeto observável, que ele se encontre no centro de um polígono perceptivo; ele pode ser percebido ou observado de ângulos diferentes (quando o observador se movimenta) e mantém-se observável quando se desloca no espaço. (A existência de um polígono perceptivo desse tipo para objetos microscópicos é sugerida por Hacking em seu argumento a partir da grade (argument from the grid), mas van Fraassen está correto em frisar que Hacking confunde um objeto, visto a partir de posições perceptivas diferentes (o caso do polígono), com dois objetos vistos a partir de posições similares). O que resulta de nossa concepção de objeto observável é que ele pode ser observado - identificado - como aquele objeto a partir de ângulos perceptivos diferentes. O observador deve estar em condição de colocá-lo no centro de um polígono perceptivo (Buekens, 1999, p. 26).

Entidades microscópicas, como elétrons e células, parecem não satisfazer esse critério. Segundo afirma Buekens, haveria um único ângulo perceptivo a partir do qual é possível ter acesso a elas, aquele fornecido pelo instrumento. Portanto, elas não se enquadrariam no critério de observabilidade proposto. Note-se que, nesse caso, a fiabilidade dos instrumentos não está em questão.

Buekens acrescenta ainda que:

Nosso conceito de objeto observável dirige-se à prática de observação de objetos e eventos comuns e macroscópicos e à nossa capacidade de seguir os rastros deles quando se movem, ou nós nos movemos, no espaço em que o objeto está localizado. Estender o conceito de observabilidade além desses limites envolve a imaginação (Buekens, 1999, p. 27).

Ora, que esse critério, que parece razoável e totalmente em sintonia com aquele de invariância, permita excluir a observabilidade de uma célula parece errado, pois essa pode ser detectada a partir de ângulos perceptivos diferentes, tanto com a utilização de um único instrumento quanto utilizando-se de instrumentos diferentes, mas aquilo que interessa salientar aqui é a ideia recorrente de percepção como ação na qual o sujeito (o corpo dele como um todo) é ativo. Há uma série de atividades que o sujeito 
percipiente desenvolve para que a percepção seja bem sucedida, não há mera passividade frente ao estímulo exterior.

Cabe notar que o critério proposto por Buekens é epistemológico, enquanto aquele de invariância é ontológico; entretanto, os dois estão certamente em consonância. Para eles vale o que foi afirmado a propósito das conexões entre o critério exposto por Ghins e as condições contrafáticas de Bueno. Com efeito, no argumento do polígono perceptivo fala-se inclusive de um deslocamento relativo entre o observador e o objeto (ou estado de coisas) percebido, que permite um rastreamento desse último por parte do sujeito, de modo que esse pode sentir-se seguro acerca do fato de estar percebendo o mesmo objeto (que mantém, segundo o observador, a própria identidade).

Em vista disso, parece possível afirmar que a percepção, mesmo quando descrita nos termos de um único órgão sensorial ("Esta goiaba tem gosto ruim"), na verdade é o resultado de uma ação complexa (ou de uma série de ações) e a consciência dessa ação em sua inteireza contribui, juntamente com a consciência (implícita, eventualmente) de que as condições contrafáticas relevantes encontram-se satisfeitas, a fazer com que o sujeito saiba que teve uma percepção verídica e bem sucedida.

Charles Taylor escreve que

nossa percepção do mundo é essencialmente aquela de um agente corporal (embodied), envolvido com, ou "por dentro de", o mundo. (...) A afirmação não é simplesmente que a percepção depende causalmente de certos estados do nosso corpo, que eu não poderia ver se meus olhos não estivessem em boas condições etc. A afirmação é, ao contrário, que nossa percepção enquanto experiência é tal que ela somente poderia ser aquela de um agente corporal envolvido com o mundo (Taylor, 1979, p. 154).

É certamente interessante relevar que essa ideia de agente corporal, que Taylor afirma estar presente em Kant e que parece estar presente também em autores contemporâneos que citamos e podemos considerar como pertencentes à tradição analítica (com todo o cuidado que a atribuição de rótulos em filosofia requer), a saber, Filip Buekens e Michel Ghins, encontra-se defendida também por um importante filósofo da tradição continental, Maurice Merleau-Ponty. Ele afirma que a experiência perceptiva nasce da relação do corpo (visto numa totalidade) com o mundo e chega até a falar de como os objetos exteriores somente podem aparecer para o sujeito em perspectiva, mas de um modo que é levado em conta pela própria percepção (cf. MerleauPonty, 1999 [1945]). Vimos a importância que a esse aspecto da percepção foi atribuída em época recente por Alva Noë. Se, por um lado, essa concepção de corpo perceptivo pode propiciar um exemplo sugestivo de paralelismo analítico/continental, por outro 
pode ser vista como um conceito transversal com relação às duas tradições (mas também ao debate entre realismo e antirrealismo em filosofia da ciência) e, por essa mesma razão, como um ponto de partida neutro e importante para um discurso acerca da observação.

Taylor afirma também que Kant operou suas deduções transcendentais a partir do insight de que devemos ter a capacidade de distinguir, na experiência, entre uma ordem objetiva das coisas e uma ordem meramente subjetiva (cf. Taylor, 1979, p. 151). Ora, o empirista van Fraassen não apela certamente para argumentos transcendentais, todavia, nesse caso, parece estar em sintonia com a ideia de Kant (e de Taylor), como pode ser depreendido na seguinte passagem:

Minhas experiências são constituídas pelos eventos que me acontecem dos quais estou ciente. Tais eventos têm duas faces, por assim dizer, aquilo que realmente me acontece e o juízo espontâneo que eu formulo como resposta, que classifica um certo evento de um determinado modo. Em casos favoráveis, os dois coincidem, mas com frequência não é esse o caso (van Fraassen, 2001, p. 158).

Ou também, na seguinte passagem de Ladyman e colaboradores:

a experiência é, do ponto de vista fenomenológico, uma experiência de nós mesmos entre, e confrontados por, coisas e eventos; talvez não possa ser diferente, talvez essa forma seja uma precondição para a própria possibilidade de uma experiência coerente (Ladyman et al., 1997, p. 320).

Estar conscientes daquilo que se experiencia equivale a dizer, no caso da percepção, que o agente tem uma exata noção não somente de qual foi o objeto da percepção, como também de como nós, enquanto sujeitos percipientes, estamos envolvidos de forma ativa nessa ação; significa também "estar presentes a nós mesmos" e sentir que o corpo todo está comprometido na percepção, concorrendo para que ela aconteça. Isso permite, também, distinguir entre uma ordem objetiva das coisas (como as coisas estão) e uma meramente subjetiva (qual é nossa resposta àquilo que está nos acontecendo, mas também quanto e de que maneira estamos envolvidos nessa percepção).

Mas o que mais importa é que essa consciência implica também em saber se todas as condições para que a percepção aconteça segundo nossos propósitos foram satisfeitas ou não e se, uma vez realizado isso, a percepção de fato aconteceu conforme planejado ou se o objeto da percepção foi outro (e qual foi). Esse tipo de consciência normalmente não está na superfície e boa parte de nossas percepções acontecem por falta (default), mas ela está disponível, caso isso se torne necessário. 
Locke já havia afirmado a necessidade de que, quando pressionado acerca de uma determinada crença, o conhecedor seja capaz de relatar de que maneira ela se formou, por exemplo falando de sua experiência (cf. Nagel, 2000, p. 347), mas isso significa também que, como disse Grice, em casos ordinários não há necessidade de justificarmos nossas crenças baseadas na observação. Nem a nós mesmos. Já vimos também que, segundo van Fraassen, para manter-se empirista sem cair no ceticismo, é legítimo recusar as demandas céticas de justificação onde não há motivo para tê-la. Contudo, como escreveu Jennifer Nagel, o fato de van Fraassen declarar-se não interessado nas garantias não significa que elas não existam. Elas residem na imediatez da experiência (cf. Nagel, 2000, p. 364). Nas palavras de van Fraassen: "Nós podemos ver, e de fato vemos, a verdade acerca de muitas coisas: de nós mesmos, dos outros, das árvores e animais, das nuvens e rios, na 'imediatez' da experiência” (van Fraassen, 1989, p. 178).

Em uma percepção genuína, temos consciência de que ela é de fato genuína, porque as condições contrafáticas relevantes estão satisfeitas e porque estivemos presentes a nós mesmos o tempo todo, cientes de que as condições para que a percepção acontecesse de forma verídica estavam satisfeitas, sabendo o que foi que vemos e tendo certeza disso porque o corpo todo se ativou para a realização dessa ação, em uma sinergia que, em casos comuns, envolve mais de um sentido ao mesmo tempo.

Isso garante que a interação com o objeto percebido possa ser qualificada como acesso epistêmico robusto, segundo a proposta de Jody Azzouni (2004). Peter Kosso (2006) e Otávio Bueno (2011) identificam, nos critérios de Azzouni, o meio de discriminar entre inferência e observação, que, para eles, assim como para Azzouni, pode acontecer, contra van Fraassen, inclusive em casos nos quais o acesso à entidade pode ser obtido somente pelo uso de instrumentos. Aquilo que interessa, pois, segundo os dois autores, não é se na detecção houve (ou não) também a intervenção de algum instrumento (como um microscópio, um telefone ou um estetoscópio) e sim se o tipo de acesso utilizado permite ter a justificação epistêmica adequada para a informação coletada. Ao endossar os critérios de independência (e robustez), refinamento e rastreamento de Azzouni, contudo, Bueno demonstra que as condições contrafáticas por ele propostas garantem a satisfação dos três requisitos e são, portanto, mais básicas (cf. Bueno, 2011, p. 279-81).

Uma percepção na qual o sujeito está consciente de como ela aconteceu e do fato de que as condições contrafáticas relevantes (na formulação mais detalhada que foi aqui apresentada) estão satisfeitas, ademais, não somente se qualifica como percepção genuína (e verídica), ou seja, como uma observação, mas também produz conhecimento, segundo a identificação entre observabilidade e inteligibilidade que é própria do empirismo. Como escreve Bueno, 
Sobre A DEFINIÇÃo DE OBSERVAÇÃo GOMo PERGEPÇÃo VERDADEIRA JUSTIFICADA

a percepção deve oferecer não apenas um processo confiável de geração de informação, mas deve ser tal que saibamos que esse processo é, de fato, confiável ou, pelo menos, devemos ter acesso aos fatores que sustentam tal confiabilidade (Bueno, 2011, p. 281).

No caso de nosso aparelho sensorial, sabemos que ele é confiável, mas não infalível. Mas, conforme foi dito anteriormente, geralmente conseguimos perceber quando ele nos está fornecendo informações duvidosas e, no mais das vezes, corrigir isso (mudando as condições perspectivas, utilizando um instrumento com sensibilidade superior àquela de nossos sentidos, perguntando para uma outra pessoa se ela está percebendo o mesmo que nós etc.). Sabemos, em outras palavras, se o processo está acontecendo de forma confiável ou não (e até geralmente como corrigi-lo, se for necessário).

Esse, aliás, parece ser o caso até de muitas detecções realizadas utilizando instrumentos, o que deveria permitir, segundo Bueno e muitos outros, traçar a linha divisória entre observável e inobservável diferentemente de onde van Fraassen considera que ela passa. Dessa maneira, abarcariam-se entre os observáveis (muitas) entidades que este último classifica, ao contrário, como inobserváveis, como é o caso das células.

Os exemplos citados por Noë, ao invés, não satisfazem esse requisito internalista. O filósofo norte-americano coloca no mesmo plano as percepções protéticas genuínas (como quando, por exemplo, uma pessoa surda consegue escutar porque se utiliza de um aparelho auditivo) e as percepções que acontecem de forma verídica, mas por meio da intervenção de agentes inteligentes (cirurgiões, anjos, pessoas). Um dos casos imaginados (ou mencionados) por Noë é aquele de um anjo pairando próximo de uma pessoa, o qual age de maneira que as experiências dessa pessoa dependam tanto de como as coisas estão quanto daquilo que a pessoa faz, satisfazendo as condições contrafáticas relevantes, pela intervenção do próprio anjo e não pelo funcionamento do sistema sensorial da pessoa (cf. Noë, 2003, p. 97-8).

Segundo Noë, essa - e o mesmo diga-se para os outros exemplos apresentados no artigo, que são totalmente análogos - pode ser considerada uma instância de percepção (protética) genuína, pelas razões vistas anteriormente. Mas isso não parece correto, como também já foi dito. Em casos como aquele de uma percepção que é sempre verídica, porque há a intervenção de um anjo que garante uma correlação entre o estado de coisas no mundo e aquilo que o sujeito percebe, de maneira a satisfazer as condições contrafáticas relevantes, pode-se dizer que o sujeito acha que sabe que tais condições estão satisfeitas, mas que na verdade não é esse o caso. ${ }^{4}$

4. Agradeço a Otávio Bueno pelos esclarecimentos a propósito dos exemplos propostos no artigo de Alva Noë. 
Em qualquer um dos exemplos de percepção anômala de Noë, não é certamente o caso que o sujeito tenha acesso aos fatores que garantem a confiabilidade do processo de geração da informação; portanto, não é correto qualificá-los como instâncias de percepção. Correto seria, em vez disso, dizer que se trata de alucinações verídicas (e que falhou, portanto, a tentativa de Noë de complementar a teoria causal de Grice, para poder separar alucinações de percepções genuínas).

Considerada a íntima relação que existe, para um empirista, entre observação e conhecimento, parece enfim possível fornecer uma definição da primeira que tem alguma analogia com a definição clássica de conhecimento como crença verdadeira justificada. Diremos que:

(1) $S$ observa e se e somente se $S$ sabe que está percebendo $e$ (de forma justificada),

onde a percepção é concebida como a satisfação das condições contrafáticas relevantes que foram expostas anteriormente e o fato de o sujeito $S$ saber que está percebendo $e$ corresponde apenas a esse estar consciente (até de forma implícita, conforme também foi explicado anteriormente) de que essas condições contrafáticas estão satisfeitas. Para tal propósito Bueno escreve que esse requisito internalista significa que "a condição contrafática não apenas é satisfeita, mas sabemos que ela é satisfeita (ao menos intuitivamente)" (Bueno, 2011, p. 284). Essa ideia, segundo a qual a consciência da satisfação das condições contrafáticas relevantes pode ser apenas intuitiva ou implícita, não parece poder ser corretamente capturada pela definição clássica de conhecimento como crença verdadeira justificada, o que torna explícito o fato de que essa não está aqui sendo empregada e sim somente evocada por uma possível analogia estrutural entre ela e a definição proposta para o ato de observação. Assim se explica também o uso da locução "saber que", a qual poderia parecer inapropriada, particularmente aos olhos de quem se reconhece na definição de conhecimento como crença verdadeira justificada. Desse modo, a definição de observação aqui proposta não parece ser herdeira dos problemas de tipo Gettier, que afligem a definição clássica de conhecimento.

Van Fraassen é um autor, entre outros, que disse claramente que a definição tripartite clássica de conhecimento deveria ser abandonada, pois esse é um conceito bem mais abrangente do que aquele capturado por tal definição. Bueno, por sua vez, não acha que a concepção tripartite do conhecimento seja adequada e, portanto, não a assume na caracterização da percepção (incluindo aquela mediada por instrumentos). Com relação ao requisito internalista, ademais, o fato de o sujeito saber que as condições contrafáticas relevantes estão satisfeitas significa meramente que ele está ciente (tem consciência) disso, às vezes nem de forma explícita, conforme foi dito, e por isso se trata de um tipo de conhecimento que não parece poder efetivamente ser capturado 
de forma satisfatória pela definição clássica e que poderia até ser atribuído a animais e bebês. É um caso de conhecimento não proposicional, conquanto, no caso de pessoas adultas, possa resultar na aquisição de crenças e, portanto, faça até sentido discutir acerca da justificação dessas crenças resultantes de uma percepção. Buekens e Muller (2012), inspirados pela obra de Dretske e pelo trabalho anterior de Buekens, identificam vários níveis no processo de observação, os mais baixos dos quais seriam a observação concebida como mero registro (algo que pode ser realizado até por aparelhos fotográficos) e a observação como registro mas com consciência do evento (realizável pelos seres humanos e por outros animais) e os mais altos seriam a observação "doxasticamente orientada" e a observação "doxástica" (que coincidiria com o "observar que" de Dretske). O segundo nível que eles identificam chama atenção, pois a capacidade de tornar-se conscientes de um determinado objeto, por tê-lo visto, pressupõe a posse de uma mente e por isso somente pode ser compartilhada por (alguns) seres vivos (cf. Buekens \& Muller, 2012, p. 94-8). Parece possível dizer que, para van Fraassen, observar coincide (ou tem início) com esse segundo nível de ver identificado por Buekens e Muller (observação como registro, mas com consciência do evento), mas que, diferentemente deles, van Fraassen considera que isso somente pode ser realizado por um ser humano, porque "observadores são acreditadores em potência”, como escreveu William Seager (1988, p. 181). Contudo, aquilo que interessa ressaltar aqui é o fato de que se por "saber que" (algo é o caso) apenas entendemos "estar ciente" (de que algo é o caso), então há autores que acham que esse tipo de conhecimento pode tranquilamente ser atribuído inclusive a animais não linguísticos.

Além disso, dessa caracterização de observação segue-se tanto que " $S$ percebe $e$ (de forma verídica)", quanto que "e (é o caso)", pelo fato de serem factivos seja o verbo "saber", seja o verbo "perceber". Assim, a analogia com a definição clássica (tripartida) de conhecimento fica de fato estabelecida.

A condição "e (é o caso)" diz respeito a como as coisas estão; posso perceber (ver, tocar, cheirar, lamber) o sorvete que está a minha frente somente se há de fato um sorvete a minha frente; se não for esse o caso (se se trata de uma alucinação), não posso.

A condição "S percebe $e$ (de forma verídica)" diz respeito à satisfação das condições contrafáticas relevantes. Se o sorvete a minha frente permanecer o mesmo, o conteúdo representacional na minha mente permanecerá o mesmo; se algo mudar (o sorvete começou a derreter, Pablo o deslocou porque queria fazer um desenho dessa guloseima, Salvador terminou a bola sabor goiaba ou eu me desloquei), então o conteúdo representacional na minha mente consequentemente mudará.

A definição-condição (1), que contém as duas condições supracitadas, diz respeito à necessidade de o sujeito $S$ saber que as condições contrafáticas relevantes estão satisfeitas (é a condição a que Bueno chama de "requisito internalista"). Se, pela in- 
tervenção de um anjo, percebo de forma verídica que há um sorvete a minha frente, estou consciente de que cada mudança em minha relação com o sorvete provoca uma consequente mudança do meu conteúdo representacional, mas não faço ideia de que é a intervenção de um anjo o fator que garante essa correlação fiável entre o estado de coisas e minha representação do mesmo, então é correto dizer que acho que sei que as condições relevantes estão satisfeitas, mas que na realidade não é esse o caso. Em outras palavras, nesse caso, não estou justificado em minha crença de que estou percebendo (um sorvete). As razões disso acabaram de ser expostas.

Se ainda subsiste uma identificação entre a observação e o conhecimento, então questões que se referem diretamente ao segundo, como o debate entre internalismo e externalismo e, de maneira mais geral, o problema da justificação de nossas crenças, podem evidentemente afetar uma discussão acerca da primeira. Não enfrentaremos essa discussão aqui, porque isso significaria desviar do propósito deste trabalho e porque, provavelmente, não seria suficiente um único estudo, todavia parece claro que, quando se fala em requisito internalista (o sujeito deve saber que está percebendo de forma verídica), isso não significa que o internalismo por si só possa dar conta de justificar nossas crenças. Uma pitada de externalismo é necessária, para não cair no solipsismo. É um sujeito diferente daquele que está percebendo, por exemplo, que pode alertá-lo de que as coisas não estão da maneira que ele pensa que estão ou, ao contrário, que pode confirmar a veracidade ou a genuinidade da percepção. Se alguém não me dissesse que, no teste de cores de Ishihara, há o número 8 escrito no cartão, eu acharia que estou vendo uma figura colorida na qual nada está escrito. Mas mesmo depois de ter recebido a informação de que ali alguém desenhou o número 8, ainda assim não consigo vê-lo e, para mim, as condições contrafáticas relevantes estão satisfeitas (descobri sofrer de uma leve forma de daltonismo somente aos 18 anos de idade, com efeito) e acho que estou percebendo um cartão colorido no qual ninguém escreveu nada. Contudo, aquilo que estou percebendo é uma figura colorida no interior da qual há, desenhado, o número 8. Ademais, sei que não estou justificado em afirmar que no cartão somente há um desenho abstrato colorido e nada mais, porque tenho ciência da minha leve forma de daltonismo. Assim Salvador, se for informado pelo amigo Pablo de que é pela intervenção de um anjo benévolo que ele está conseguindo escutar Edith Piaf cantando, mas que na verdade está surdo desde que recebeu aquela bofetada de sua musa Gala, vai dar-se conta de que ele acha que está escutando a cantora francesa, mas que na verdade não está. Enfim, como último exemplo, podemos pensar no recente caso, acontecido no interior paulista, de um velório durante o qual entrou na sala a pessoa que estava (supostamente) sendo velada (evidentemente houve um erro de identificação de um cadáver encontrado na cidade). Houve espanto por parte dos familiares, quando viram o falecido na porta da sala onde o corpo estava sendo velado, 
como se pode imaginar. Ora, é bem provável que a primeira pessoa que viu o indivíduo em questão tenha duvidado daquilo que estava vendo e tenha chamado a atenção dos outros presentes, para que eles também olhassem para a mesma direção. Apesar de estar tendo uma percepção verídica, o sujeito teve motivos para duvidar dela e precisou, para corroborar sua percepção, confrontá-la com aquela de outrem. Uma vez confirmado que os outros presentes estavam vendo o mesmo que ele, o sujeito soube que estava efetivamente olhando para seu parente que todo mundo achava que tivesse morrido (e que não estava sonhando ou alucinando).

Ora, o problema de uma caracterização por meio de uma definição é que, em princípio, corre-se o risco de a analogia com a famosa definição tripartida de conhecimento chegar até o ponto de alguém encontrar, inclusive para a observação, situações de "tipo Gettier", ou seja, casos de percepção verdadeira justificada que não corresponderiam a instâncias de observação. A analogia não pode ser completa, porém, porque a definição de observação fornecida (admitindo que possa legitimamente ser chamada assim) é sem dúvida descritiva, por limitar-se a tentar capturar as características ou propriedades dessa ação, tornando explícito (e adequando-se a) aquilo que é corriqueiro e familiar, enquanto a definição clássica de conhecimento se parece muito mais com uma definição do tipo da estipulação. Ademais, o requisito internalista do qual falamos deveria normalmente impedir que até para a observação possam surgir situações de "tipo Gettier".

É nossa convicção que essa caracterização de observação - como percepção verdadeira justificada (internalisticamente) - deveria servir, entre outras coisas, para suportar o empirismo construtivo. Com efeito, vários autores relevaram como, apesar de a questão da observabilidade desempenhar um papel crucial para essa vertente antirrealista, não está claro o que significa, para van Fraassen, observar.

Segundo Elliott Sober, por exemplo, já que a distinção entre observáveis e inobserváveis é central para o empirismo do filósofo holandês, seria oportuno que ele fornecesse um relato do que significa observar um objeto. Em A imagem científica, ao contrário, van Fraassen deixou claro que é uma questão empírica a ser respondida pela ciência e não um assunto para análise filosófica. Mas se é uma questão empírica descobrir quais são as capacidades observacionais dos seres humanos, isso não isenta os empiristas da obrigação de dizer quais são os aspectos que se encontram envolvidos na ação descrita como "observar algo" (cf. Sober, 2008, p. 13o-1).

O propósito deste artigo foi oferecer uma caracterização da observação que permita cumprir com essa obrigação. Ela é, evidentemente, parasitária de uma caracterização da percepção satisfatória, mas acreditamos que, para suportar a distinção fraasseniana entre observável e inobservável, aquela fornecida aqui seja suficiente. 
Ademais, apesar de poder ser utilizada como argumento para defender que entidades que van Fraassen notoriamente considera inobserváveis, como os paramécios, são na verdade observáveis, ela certamente não permite pensar que não existe uma distinção entre observável e inobservável ou que toda entidade postulada pela ciência é, afinal, observável. O requisito internalista, de o sujeito ter que saber que o processo de geração da informação é de fato confiável, bloqueia essa possibilidade (cf. Bueno, 2011, p. 289) e isso garante que, graças à definição proposta, os alicerces do empirismo construtivo tenham a solidez necessária para sustentar a construção filosófica do autor de $A$ imagem científica. $\oplus$

Agradecimentos. O presente trabalho se beneficiou de conversas esclarecedoras com o Prof. Otávio Bueno, da University of Miami (EUA), ao qual registro meu agradecimento. Gostaria ainda de agradecer aos pareceristas anônimos da Revista pelos comentários e sugestões enriquecedores à primeira versão deste texto.

Alessio GAva Departamento de Filosofia, Universidade Federal de Minas Gerais, Belo Horizonte, Brasil. alessiogava@yahoo.it

\title{
On the definition of observation as justified true perception
}

\begin{abstract}
The primacy of the act of observation, one of the hallmarks of empiricism, found new life in the centrality of the distinction, made in Bas van Fraassen's constructive empiricism, between observable and unobservable. As Elliott Sober (and others) have pointed out, however, it is not clear what van Fraassen understands by observing an object. Worse, the Dutch philosopher does not seem to consider that a clarification of this point is necessary. This, of course, represents an important lacuna in a position generally considered as the main reference for modern empiricism. My goal is to take up again the counterfactual conditionals characterizing perception that Otávio Bueno presented in 2011 in this journal, and also to consider the observability and the existence criteria proposed by Filip Buekens and Michel Ghins, in order to get to a definition of observation that should give van Fraassen's observability concept the support it actually lacks, but without presenting itself as an ad hoc solution.
\end{abstract}

KeYwords $\bullet$ Observation. Perception. Observability. Relevant counterfactuals. Constructive empiricism. Van Fraassen. Buekens. Bueno. Ghins. Noë. 


\section{REFERÊNGIAS BIBLIOGRÁFIGAS}

Azzouni, J. Deflating existential consequence: a case fornominalism. New York: Oxford University Press, 2004. Buekens, F. Observing in a space of reasons. 1999. Disponível em: <http://drcwww.uvt.nl/ buekens/ obs.doc>. Acesso em: 11 jun. 2007.

Buekens, F. \& Muller, F. A. Intentionality versus constructive empiricism. Erkenntnis, 76, p. 91-100, 2012. Bueno, O. A evidência visual na ciência. Scientix Studia, 9, 2, p. 267-90, 2011.

Constructive empiricism, partial structures and the modal interpretation of quantum mechanics. Quanta, 3, 1, p. 1-15, 2014.

. Quase-verdade: seu significado e relevância. In: MAtos, D. (Ed.). Newton da Costa, 80 anos. João Pessoa: Editora da Universidade Federal da Paraíba. No prelo.

Carnap, R. Empiricism, semantics and ontology. Revue Internationale de Philosophie, 4, p. 20-4,O, $195^{\circ}$.

CARtwright, N. Why be hanged for even a lamb? In: Monton, B. (Ed.). Images of empiricism. Essays on science and stances, with a reply from Bas C. van Fraassen. Oxford: Clarendon Press, 2007. p. 32-44.

Chakravarttry, A. A metaphysics for scientific realism: knowing the unobservable. New York: Cambridge University Press, 2007.

GHANG, H. Acase for old-fashioned observability, and a reconstructed constructive empiricism. Philosophy of Science, 72, 5, p. 876-87, 2005 .

Fine, A. \& Leplin, J. (Ed.). Philosophy of Science Association Proceedings 1988. v. 1: Contributed papers.

Ghins, M. Can common sense realism be extended to theoretical physics? Logic Journal of the IGPL, 13,1 , p. 95-111, 2005.

Grice, H. P. The causal theory of perception, part 1. Proceedings of the Aristotelian Society, 35, p.121-52, 1961.

Humphreys, P. Extending ourselves. Computational science, empiricism, and scientific method. New York: Oxford University Press, 2004.

Kosso, P. Detecting extrasolar planets. Studies in History and Philosophy of Science, 37, 2, p. 224,-36, 2006.

Ladyman, J. et al. A defence of van Fraassen's critique of abductive inference: reply to Psillos. The Philosophical Quarterly, 47, 188, p. 3०5-21, 1997.

Matos, D. (Ed.). Newton da Costa, 80 anos. João Pessoa: Editora da Universidade Federal da Paraíba. No prelo.

Merleau-Ponty, M. Fenomenologia da percepção. Tradução C. A. R. de Moura. São Paulo: Martins Fontes, 1999 [1945].

Monton, B. (Ed.). Images of empiricism. Essays on science and stances, with a reply from Bas C. van Fraassen. Oxford: Clarendon Press, 2007.

NAGEL, J. The empiricist conception of experience. Philosophy, 75, 3, p. 345-76, 2000.

Nö̈, A. Causation and perception: the puzzle unravelled. Analysis, 63, 2, p. 93-100, 2003.

Psillos, S. \& Curd, M. (Ed.). The Routledge companion to the philosophy of science. New York: Routledge, 2008.

Seager, W. Scientific anti-realism and the epistemic community. In: Fine, A. \& LePLin, J. (Ed.). Philosophy of Science Association Proceedings 1988. v. 1: Contributed papers, p. 181-7.

Sober, E. Empiricism. In: Psillos, S. \& Curd, M. (Ed.). The Routledge companion to the philosophy of science. New York: Routledge, 2008. p. 129-38.

TAYLOR, C. The validity of transcendental arguments. Proceedings of the Aristotelian Society,79, p. 151-65, 1979.

Van Fraassen, B. C. The scientific image. Oxford: Clarendon Press, 1980. . Laws and symmetry. Oxford: Clarendon Press, 1989. . Constructive empiricism now. Philosophical Studies, 106, 1-2, p. 151-70, 2001. . A imagem científica. Tradução L. H. de A. Dutra. São Paulo: Editora Unesp/Discurso Editorial, 2007. Scientific representation: paradoxes of perspective. Oxford: Clarendon Press, 2008. 